\title{
Migration, environment, and country safety: analysis of touchpoints
}

\author{
.Iryna Didenko ${ }^{1 *}$, Kseniia Volik $^{2}$, Tetiana Vasylieva $^{3}$, Serhiy Lyeonov ${ }^{1}$ and Nataliia \\ Antoniuk $^{3}$ \\ ${ }^{1}$ Sumy State University, Economic Cybernetics Department, 40000 Sumy, Ukraine \\ ${ }^{2}$ Sumy State University, Department of Economics, Entrepreneurship and Business Administration, \\ 40000 Sumy, Ukraine \\ ${ }^{3}$ Sumy State University, Department of Finance and Entrepreneurship, 40000 Sumy, Ukraine
}

\begin{abstract}
This study presents the results of bibliometric analysis of publications that are thematically related to migration, environment, and safety. Vosviewer software helped to analyze the co-use of keywords in these publications, and the authors' affiliation to specific countries was performing. The works for the period 1965-2019, indexed by the scientometric database Scopus, were taken for analysis. With the help of Scopus analytical resources, and analysis of the dynamics of publication activity on the research issue was performing. The study found that scientists made the most significant number of publications related to migration, environment, and safety from the United States and the United Kingdom. The analysis by keywords showed that the concepts of migration, environment, and safety often intersect, which indicates the possibility and necessity of their joint research to identify key factors influencing these phenomena.
\end{abstract}

\section{Introduction}

Migration, environment, and safety are the categories that always arouse increased interest among both the scientific and political community because these phenomena affect the socioeconomic development of society in a country and humanity as a whole.

Climate change, natural disasters, air pollution, land, and water resources are phenomena that occur in the environment and pose a potential threat to healthy human life. Unsatisfactory environmental conditions can force people to change their place of residence in search of better living conditions. In the event of sudden large-scale disasters, such as hurricanes, tsunamis, and floods, many people are forced to leave their homes and go into the unknown. Also, changes in the environment affect the country's security, as additional resources are needed to combat their consequences. At the same time, there may be an increase in unemployment and social inequality, causing the deterioration of the environmental situation [1-5]. That is why An important issue is identifying and studying the relationship between these concepts to build a balanced migration and environmental policy that will strengthen

* Corresponding author: iryna.didenko2011@gmail.com 
the country's security. And for this, you need to understand how the studied notions can intersect with each other in research.

\section{Methodology}

The search was performing in the title of the publications, their short description, and keywords to them. The search takes place for the period from 1965 to 2019. Also, we limited the search query to the knowledge area. The search is carrying out in such areas as Social Sciences, Environmental Sciences, Agricultural, and Biological Sciences, Economics, Econometrics and Finance, Arts and Humanities, Business, Management and Accounting, Multidisciplinary, Decision Sciences. Areas of knowledge that are not relevant to our study are also excluding from the search query.

As a result, 454 documents were received, including 288 articles, 65 book chapters, 37 books, 35 reviews and 18 conference papers. Vosviewer software will be used to analyze bibliometric networks. Since Vosviewer is an English-language program, publications written in English were used for the study.

\section{Results and discussion}

This study bases on information from the scientometric and abstract database "Scopus". Terms such as "environment", Research in the field of migration, environment, and safety of the country is diverse, which is associated with a wide range of problems in these areas. Research on this issue is dividing into several groups, which are linked by a prevailing direction. The first group includes works that study environmental factors that are the driving force of internal and external migration around the world and a threat to national safety [19]. The following group of publications reveals the importance of studying the indirect factors influencing climate and safety, including the impact of agriculture, food prices, economic growth, migration, disasters, money laundering, international and domestic institutions [918].

The opinion of a group of scientists about the consideration of ecological migration is from the standpoint of a social phenomenon. In this aspect, the situation of vulnerable migration groups is considering, which, due to unfavorable environmental conditions, are forced to leave their place of residence and seek refuge elsewhere [19-20]. Emphasis is placed on the importance of lifelong learning to ensure a dignified existence in new home [21-22]. Another group of studies that are singling out is the study of strategies for adapting to climate change to protect environmental migrants from ensuring the country's safety of the country [23-27]. The issues of adaptation are surprisingly important, as their study can prevent ecological changes, thereby eliminating their negative consequences for the population.

Among the research, areas are aimed at analyzing environmental indicators to build a balanced policy to ensure the safety of the country, particularly in ecology, energy, and food [28-37]. Researchers are studying the impact of population migration on the safety of countries [32] and the impact of migration in rural areas in terms of sustainable development [38-45].

Thus, migration, environment, and safety of the country intersect in various areas of research, thus giving scientists a wide field for scientific advances.

Over the last decade, issues related to migration, environment, and safety have begun to receive more attention (Fig. 1). Until 1990, there was almost no combination of such concepts in the scientific community of the world. Since 1990 there have been about 2-5 publications per year related to the research topic. The study of the relationship between these concepts in recent years is a very relevant subject. 


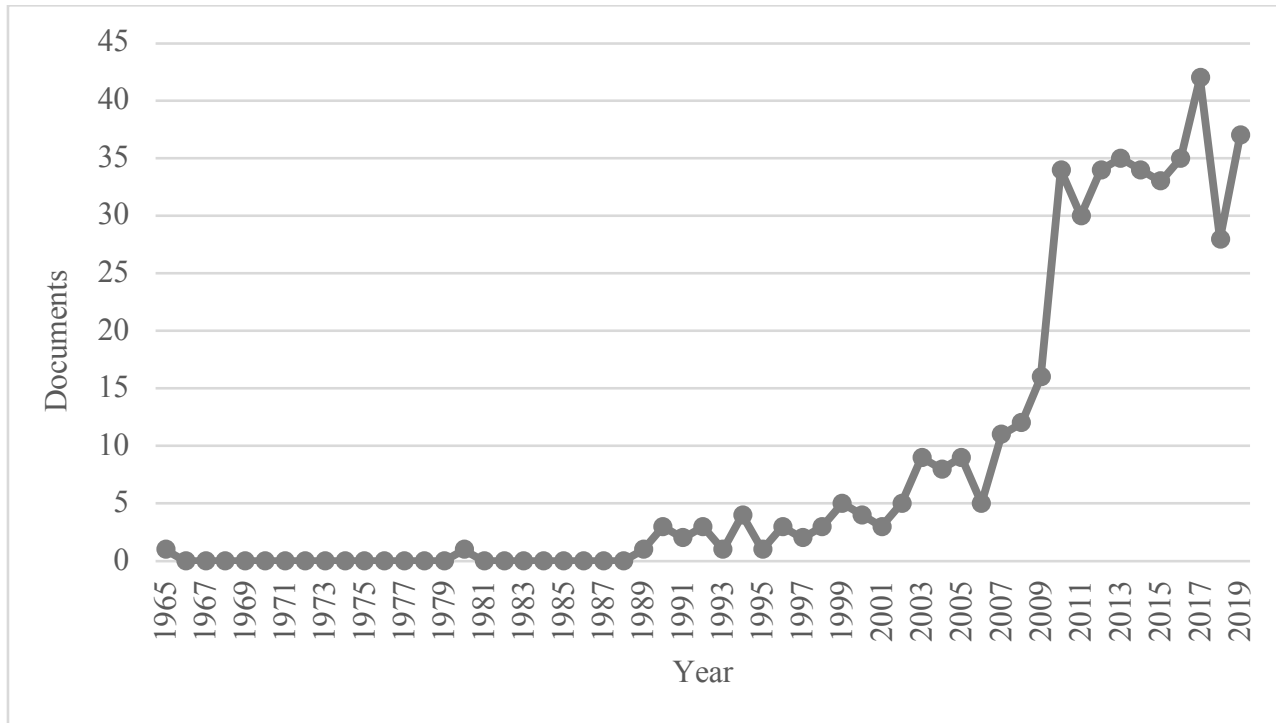

Fig. 1. Dynamics of publications about migration, environment and safety in Scopus

An essential point in the implementation of bibliometric research is the analysis of publication activity about countries, as it allows us to understand which countries the selected issues are particularly relevant. According to Scopus, the study by countries showed that scientists from the USA (116 files), Great Britain (71 files), Canada (35 files), Germany (32 files), and others are mainly engaged in migration, environment and safety studies. It should be noted that states do not conduct research separately from each other. Still, in cooperation with other states, this issue is not a particular problem of an individual country but is the concern of most countries. Figure 2 shows the countries that have dealt with this issue, and the lines indicate the links between countries, i.e., with which states have cooperated in researching this topic. As you can see, the United States, Great Britain, and Canada have the most significant connections. 


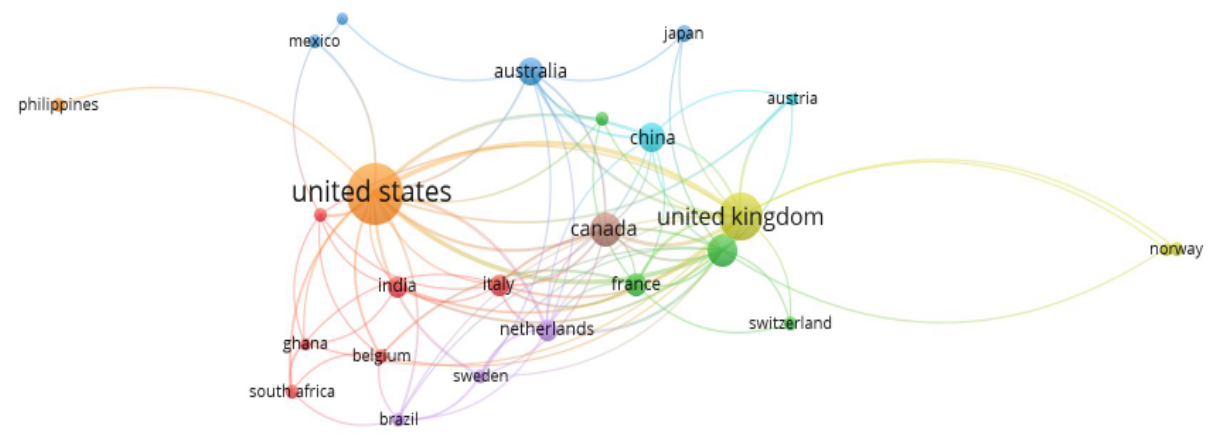

Vosviewer

Fig. 2. Belonging of scientists to countries that have analyzed issues related to migration, environment and safety

The analysis of joint activities by keywords for selected publications on migration, environment, and safety allowed to single out five clusters based on 140 keywords (Fig. 4). The most significant number of occurrences are such keywords as migration (92 files), climate change (68 files), food safety (62 files), safety (29 files), environment protection (26 files), environment (20 files), and others. These five clusters together have a total of links between keywords 3203 and a total strength of 5701 .

The first cluster is in red, it is the largest and includes 49 keywords, the most important of which are migration, which has 127 links, and therefore related to most keywords, climate change with 118 links and food safety, which has 110 links. The importance of these terms is explaining by the number of publications in which they occurred. The terms migration and climate change are next to each other, which suggests a close connection between them and the fact that they often appeared together in publications. In addition to climate change and migration, the papers included such concepts as environment, environmental factors, environmental policy, environmental protection, environmental management, environmental migration, environmental safety, food safety, safety, social safety, and human safety. The first cluster also contains the term safety, which has 66 references and is in papers along with such concepts as migration, international migration, environment, environmental change, climate change, environmental risk and environmental safety, national safety.

The second cluster is green and includes 29 keywords. This cluster covers more of the biological field, as most of the keywords are related to wildlife. This cluster is the term environmental impact, which occurs in works and concepts such as migration and food safety.

The third cluster represents in blue, which includes 24 keywords. This cluster combines terms related to safety, migration, and society. The essential condition of this cluster is international migration, which occurs in publications along with such keywords as migration, safety, climate change, environment, and environmental protection.

The fourth cluster is yellow. It includes 23 key concepts that are more related to economic phenomena. This cluster provides the environment and migration policy. It mentions above 
what concepts the environment related to migration policy encounters in publications. This term is used in scientific works with such keywords as migration, climate change, and the environment.

The fifth cluster is the smallest in terms of keywords, only 15 of them. This cluster includes terms that are more related to environmental protection. The most important word in this cluster is environmental protection. This term occurs in publications together with migration, climate change, safety, food safety, national safety, and international migration.

\& VOSviewer

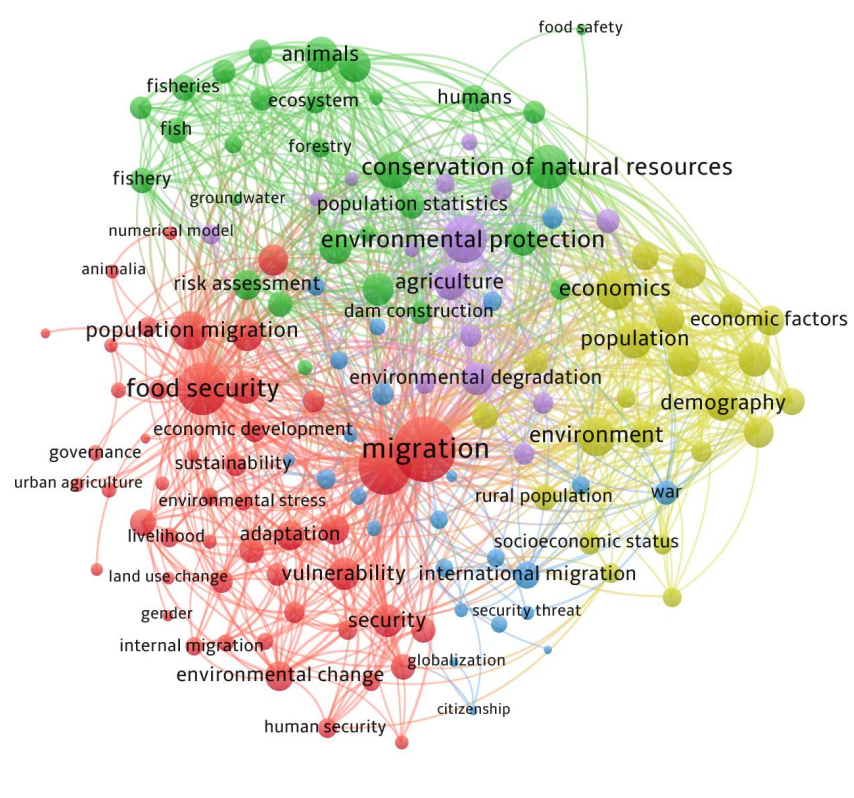

Fig.4. Scientometric map by keywords of selected publications indexed by Scopus

Vos viewer also allows you to view a chronological display of changes in keyword usage (Fig. 5). Blue illustrates earlier keywords, yellow shows relatively new concepts. We can say that the first studies are more concerned with the fundamentals of demography, the environment, the economy. More original research focuses on migration, security, the biological sphere, climate change, and more. It is worth noting that the concept of environmental migration is entirely new, describing the phenomenon of human resettlement related to ecology. This term links migration to the environment. 
\& VOSviewer

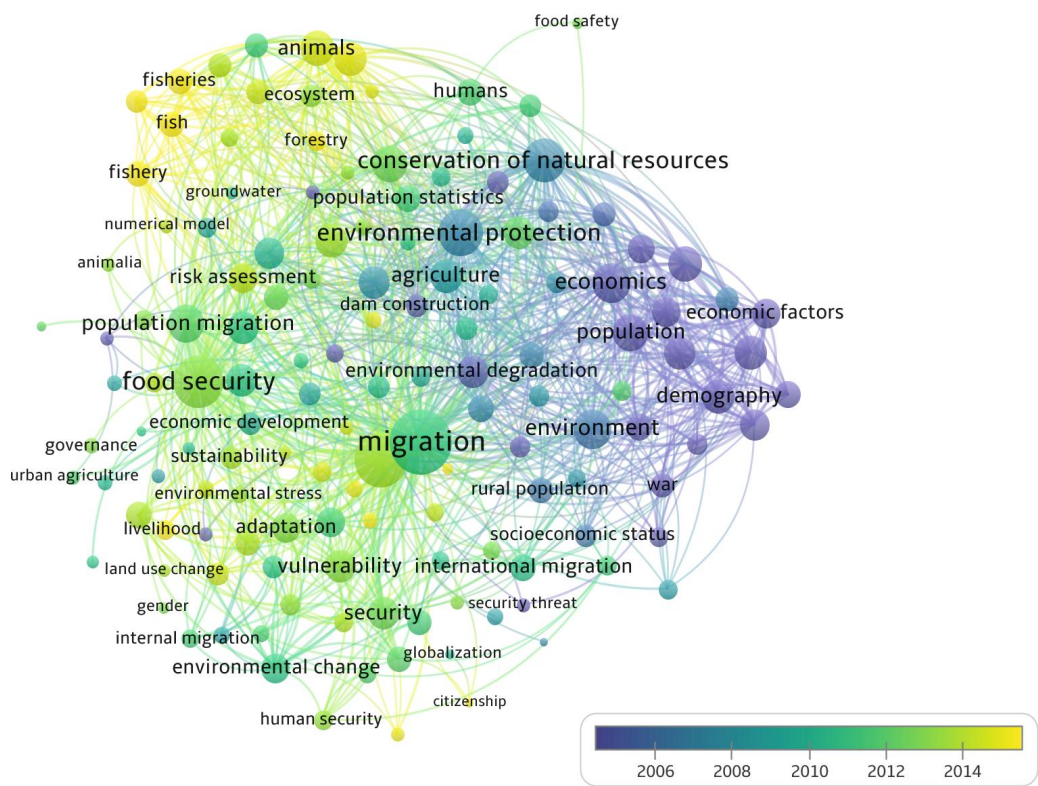

Fig. 5. Chronological display of scientometric map by keywords of selected publications indexed by Scopus

\section{Conclusion}

The study showed that in recent years there had been an increase in interest in studying issues related to migration, environment, and security, which indicates the increasing importance of this area of knowledge. Scientists from the United States and the United Kingdom make the most significant contribution to the development of ideas about the research question.

With the help of Vosviewer software, 454 publications were clustered by keywords. As a result of the analysis, the key concepts were divided into five clusters. The first cluster was the largest and included the essential concepts most commonly found in publications. The study of keyword coexistence revealed that areas of knowledge such as migration, environment, and security often intersect in research, indicating that there are links between these phenomena that need to be studied in detail. In general, the selected five clusters conditionally reflect the most common areas of promising research. These studies can be based not only within the cluster, but also between several clusters.

\section{Acknowledgment}

The survey was supported by the Ministry of Education and Science of Ukraine and performed the results of the projects 0118 U003569 and 0120U102001 


\section{References}

1. S. Blondi, Cent. Asian Surv. 38, 2. 275-292 (2019)

2. K. M. McFarland, Dev. (Basingstoke). 59, 3-4. 217-222 (2016)

3. E. Seiyefa, Afr. Secur. Rev. (2019) (to be published)

4. W. F. G. Cardy, Hum. Impact Environ. Sustain. Dev. Africa. 141-161 (2018)

5. N. Suckall, E. Fraser, P. Forster, Clim. Dev. 9, 4. 298-312 (2017)

6. S. Lyeonov, T. Pimonenko, Y. Bilan, D. Štreimikiene, G. Mentel, Energies. 12, 20 (2019)

7. F. Gemenne, State of the World 2015: Confronting Hidden Threats to Sustainability. 117-126 (2015)

8. R. P. Marzec, Militarizing the environment: Climate change and the security state. 1305 (2015)

9. J. McGregor, Food Policy. 19, 2. 120-132 (1994)

10. J. Busby, Curr. Clim. Change Rep. 4, 4. 338-346 (2018)

11. Y. Bilan, T. Vasilyeva, S. Lyeonov, K. Bagmet, Bus.: Theory Pract. 20. 103-115 (2019)

12. T. Vasilyeva, S. Bilan, K. Bagmet, R. Seliga, Econ. Soc. 13, 1. 271-294 (2020)

13. S. Leonov, H. Yarovenko, A. Boiko, T. Dotsenko, Information system for monitoring banking transactions related to money laundering, in Proceedings of the 8th International Conference on Monitoring, Modeling and Management of Emergent Economy, M3E2-EEMLPEED, 22-24 May 2019, Odessa, Ukraine (2019)

14. V. Levchenco, A. Boyko, V. Bozhenko, S. Mynenko, Bus.: Theory Pract. 20. 492-508 (2019)

15. I. Kendiukhov, M. Tvaronaviciene, MMI. 3. 33-42 (2017)

16. Y. Bilan, T. Vasilyeva, O. Lyulyov, T. Pimonenko, Int. J. Bus. Soc. 20, 2. 433-450. (2019) URL: http://www.ijbs.unimas.my/images/repository/pdf/Vol20-no2-paper1.pdf.

17. Y. Bilan, A. G. Raišienè, T. Vasilyeva, O. Lyulyov, T. Pimonenko, Public Policy Adm. 18, 2. 241-255 (2019)

18. C. Methmann, A. Oels, Secur. Dialogue. 46, 1. 51-68 (2015)

19. R. Ahsan, South Asia Res. 39, 2. 184-201 (2019)

20. L. English, P. Mayo, Int. Rev. Edu. 65, 2. 213-231 (2019)

21. S. Pryima, Y. Dayong, O. Anishenko, Y. Petrushenko, A. Vorontsova, Probl. \& Perspect. Manag. 16, 3. 1-13 (2018)

22. B. McFarland, Int. Rev. Sociol. 29, 2. 159-171 (2019)

23. P. Aniah, M. Kaunza-Nu-Dem, J. Ayembilla, Heliyon. 5, 4 (2019)

24. T. Hodgetts, D. Burnham, A. Dickman, E. Macdonald, D. Macdonald, Conserv. Biol. 33, 2. 250-259 (2019)

25. M. Krishnapillai, Clim. Change Manag. 101-117 (2017)

26. L. Nishimura, Int. J. Refug. Law. 27, 1. 107-134 (2015)

27. H. Dkhili, MMI. 3. 333-344. (2018) http://doi.org/10.21272/mmi.2018.3-30

28. Y. Bilan, S. Lyeonov, N. Stoyanets, A. Vysochyna, IJETM. 21, 5-6. 289-305 (2018)

29. C. Rudolph, Am. Polit. Sci. Rev. 97, 4. 603-620 (2003)

30. O. Lyulyov, T. Pimonenko, N. Stoyanets, N. Letunovska, RWE. 10, 4. 97-105 (2019) 
31. L. M. Hunter, S. Leyk, G. J. Maclaurin, R. Nawrotzki, W. Twine, B. F. N. Erasmus, M. Collinson, Comp. Popul. Stud. 42. 117-148 (2017)

32. G. Lui, H. Wang, Y. Cheng, B. Zheng, Z. Lu, Land Use Policy. 59. 569-579 (2016)

33. L. Mura, M. Marchevska, M. Dubravska, MMI. 4. 203-211. (2018) http://doi.org/10.21272/mmi.2018.4-18

34. T. Vasylieva, Yu. Bilan, I. Tiutiunyk, T. Pisula, Countries financial development and digital readiness as determinants of financial sector innovativeness, in Proceedings of the 34rd International Business Information Management Association Conference, IBIMA, 13-14 November 2019, Madrid, Spain (2019)

35. S. Lyeonov, Yu. Bilan, P. Rubanov, A. Grenčíková, Countries Financial Development and Digital Readiness as Determinants of Financial Sector Innovativeness, in Proceedings of the 34rd International Business Information Management Association Conference, IBIMA, 13-14 November 2019, Madrid, Spain (2019)

36. Y. Bilan, S. Lyeonov, T. Vasylieva, Y. Samusevych, Online J. Model. the New Europe. 27. 34-66 (2018)

37. Y. Bilan, P. Rubanov, T. Vasylieva, S. Lyeonov, Pol. J. Manag. Stud. 19, 1. 70-93 (2019)

38. Y. Bilan, M. Brychko, A. Buriak, T. Vasilyeva, Zb. Radova Ekon. Fak. au Rijeci. 37, 1. 113-138 (2019)

39. Y. Bilan, T. Vasilyeva, O. Kryklii, G. Shilimbetova,. Creat. Stud. 12, 1. 75-101 (2019)

40. T. Vasilyeva, O. Kuzmenko, V. Bozhenko, O. Kolotilina, Assessment of the dynamics of bifurcation transformations in the economy, in Proceedings of the 8th International Conference on Monitoring, Modeling and Management of Emergent Economy, M3E2EEMLPEED, 22-24 May 2019, Odessa, Ukraine (2019)

41. Y. Bilan, S. Lyeonov, O. Lyulyov, T. Pimonenko, Pol. J. Manag. Stud. 19, 2. 61-74 (2019)

42. Y. Bilan, Đž. Đšuzmenko, A. Boiko, Research on the impact of industry 4.0 on entrepreneurship in various countries worldwide, in Proceedings of the 33rd International Business Information Management Association Conference, IBIMA, 10 11 April 2019, Granada, Spain (2019)

43. Y. Petrushenko, N. Kostyuchenko, Y. Danko, Actual Probl. Econ. 159, 9. 257-263. (2014) URL:

http://webcache.googleusercontent.com/search?q=cache:U0g3tcIVSjwJ:irbisnbuv.gov.ua/cgi-

bin/irbis_nbuv/cgiirbis_64.exe\%3FC21COM\%3D2\%26I21DBN\%3DUJRN\%26P21D BN\%3DUJRN\%26IMĀGE_FILE_DOWNLOAD\%3D1\%26Image_file_name\%3DPD F/ape_2014_9_33.pdf $+\& \mathrm{~cd}=2 \& \mathrm{hl}=\mathrm{ru} \& \mathrm{ct}=\mathrm{clnk} \& \mathrm{gl}=\mathrm{ua}$

44. A. GrenÄ ÃkovÃ $i$, Y. Bilan, Y. Samusevych, A. Vysochyna, Drivers and inhibitors of entrepreneurship development in central and eastern European countries, in Proceedings of the 33rd International Business Information Management Association Conference, IBIMA, 10-11 April 2019, Granada, Spain (2019)

45. H. Shvindina, Safety. 5, 3 (2019) 